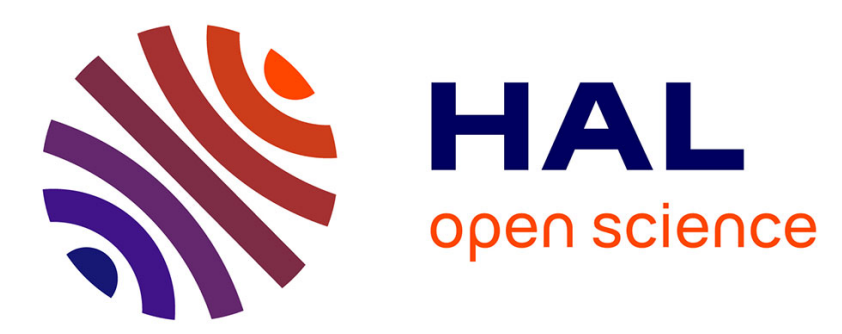

\title{
Supercritical water (SCW) investigations in the DECLIC and DECLIC-Evo: Past, present and future
}

Michael D. Hicks,, Uday G. Hegde, Carole Lecoutre, Samuel Marre, Yves

Garrabos

\section{- To cite this version:}

Michael D. Hicks, Uday G. Hegde, Carole Lecoutre, Samuel Marre, Yves Garrabos. Supercritical water (SCW) investigations in the DECLIC and DECLIC-Evo: Past, present and future. Acta Astronautica, 2020, 176, pp.59-68. 10.1016/j.actaastro.2020.06.006 . hal-02874739

\section{HAL Id: hal-02874739 \\ https://hal.science/hal-02874739}

Submitted on 30 Jun 2020

HAL is a multi-disciplinary open access archive for the deposit and dissemination of scientific research documents, whether they are published or not. The documents may come from teaching and research institutions in France or abroad, or from public or private research centers.
L'archive ouverte pluridisciplinaire HAL, est destinée au dépôt et à la diffusion de documents scientifiques de niveau recherche, publiés ou non, émanant des établissements d'enseignement et de recherche français ou étrangers, des laboratoires publics ou privés. 


\section{Journal Pre-proof}

Supercritical water (SCW) investigations in the DECLIC and DECLIC-Evo: Past, present and future

Michael C. Hicks, Uday G. Hegde, Carole Lecoutre, Samuel Marre, Yves Garrabos

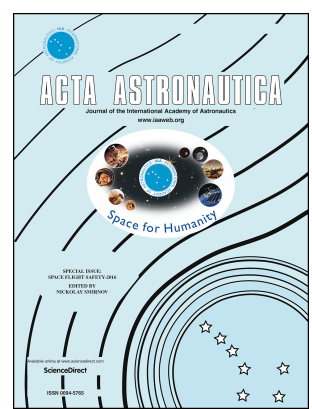

PII:

S0094-5765(20)30353-2

DOI: https://doi.org/10.1016/j.actaastro.2020.06.006

Reference: $\quad$ AA 8113

To appear in: Acta Astronautica

Received Date: 3 February 2020

Revised Date: 18 May 2020

Accepted Date: 2 June 2020

Please cite this article as: M.C. Hicks, U.G. Hegde, C. Lecoutre, S. Marre, Y. Garrabos, Supercritical water (SCW) investigations in the DECLIC and DECLIC-Evo: Past, present and future, Acta Astronautica (2020), doi: https://doi.org/10.1016/j.actaastro.2020.06.006.

This is a PDF file of an article that has undergone enhancements after acceptance, such as the addition of a cover page and metadata, and formatting for readability, but it is not yet the definitive version of record. This version will undergo additional copyediting, typesetting and review before it is published in its final form, but we are providing this version to give early visibility of the article. Please note that, during the production process, errors may be discovered which could affect the content, and all legal disclaimers that apply to the journal pertain.

(C) 2020 Published by Elsevier Ltd on behalf of IAA. 
$[$ Script $=$ Greek, Scale $=$ MatchUppercase, Ligatures $=$ TeX $]$ Liberation Serif 


\title{
Supercritical Water (SCW) Investigations in the DECLIC and DECLIC-Evo: Past, Present and Future
}

\author{
Michael C. Hicks \\ NASA - Glenn Research Center, Cleveland, Ohio 44135, USA \\ Uday G. Hegde \\ Case Western Reserve University, Cleveland, Ohio 44135, USA \\ Carole Lecoutre, Samuel Marre, Yves Garrabos \\ CNRS, Univ. Bordeaux, Bordeaux, ICMCB, UMR 5026, F-33600, Pessac, France
}

\begin{abstract}
A series of microgravity investigations have been formulated to be performed in the DECLIC and DECLIC-Evo on board the International Space Station to provide a better understanding of fundamental processes that take place in water solutions at near-critical conditions. These investigations rely on the design heritage of an earlier fundamental physics study that explored the nearcritical behavior of pure water and for which the High Temperature Insert (HTI) was originally designed and built. The experiments also have the overarching goal of providing some of the scientific underpinnings for future advances in supercritical water oxidation (SCWO) technologies.

SCWO technology is one of NASAs candidate technologies for waste management and resource reclamation for extraterrestrial missions. However, during typical SCWO reactions, inorganic salts present in the reactant stream will precipitate and coat reactor surfaces and control mechanisms, often severely impacting the systems performance. The first of the considered experiments, the Supercritical Water Mixture (SCWM) experiment, is a phenomenological study to provide observations of the phase separation and transport mechanisms of salt precipitate of a dilute solution of $\mathrm{Na}_{2} \mathrm{SO}_{4} 0.5 \%-\mathrm{w}$ (aq) at 0 -g. In the absence of gravity a unique window for observation of a variety of near-critical physical phenomena is made possible. Observations of this dilute solution have shown striking differences from pure water in its incipient boiling processes, trans-critical phase partitioning, and density stratification as influenced by an overlay of concentration and temperature gradients.

A subsequent experiment, SCWM-2, is planned that will expand on the science obtained in SCWM, using the same High Temperature Insert (HTI), which is to be refurbished and filled with a different test solution. A third microgravity experiment, SCWO-D, will then allow for observations of autoignition and stabilization
\end{abstract}

\footnotetext{
* Corresponding Author

Email address: michael.c.hicks@nasa.gov (Michael C. Hicks)
} 
of hydrothermal flames in supercritical water. This final experiment will require a significant insert redesign to accommodate a flow system and a properly designed test cell for observations of small hydrothermal flames without quenching. Additionally, significant ground development work is underway in support of the science associated with the generation and stabilization of hydrothermal flames. The science team at the University of Bordeaux is developing the micro-fluidic devices to support the miniaturized infrastructure for the flow system. The science team at NASA Glenn Research Center is currently developing the science behind the autoignition and stabilization of hydrothermal flames. Preliminary findings of the SCWM experiment and progress in the development of the SCWM-2 and SCWO-D experiments will be discussed in this work.

Keywords: hydrothermal flame, supercritical water oxidation, jet injection, high pressure

\section{Nomenclature}

CNES Centre National d'Etudes Spatiales

NASA National Aeronautic and Space Administration

ICMCB Institut de Chimie de la Matire Condense de Bordeaux

SCWM Supercritical Water Mixture

SCWO Supercritical Water Oxidation

DECLIC Device for the Study of Critical Liquids and Crystallization

DECLIC-Evo DECLIC-Evolution

SCWO-D SCWO in DECLIC-Evo

HTI High Temperature Insert

HTI-R HTI-Refurbishment

SCU Sample Cell Unit

\section{Introduction}

A major programmatic element of the DECLIC Facility that was conceived, designed, built and operated by Centre National d'Etudes Spatiales (CNES) incorporates a series of investigations to advance SCWO technology for space exploration missions. This suite of flight investigations, heavily leveraged off the original High Temperature Insert (HTI) flight investigation, have become the foundation of a successful scientific collaboration between NASA and CNES. [1]

This paper provides a discussion of three flight investigations; one that has been performed in the Device for the Study of Critical Liquids and Crystallization (DECLIC) Facility and two that will be carried out in the new DECLIC-Evolutionary (DECLIC-Evo) Facility, on board the International Space Station (ISS). 
water and dilute salt aqueous systems at near-critical conditions for the purpose of establishing the scientific underpinnings for the advancement of supercritical water oxidation (SCWO) technologies.

For reasons to be discussed in the following section, SCWO technology is one of NASAs candidate technologies for waste management and resource reclamation for extraterrestrial missions. However, in order to bring this technology to a point where it can successfully be applied for NASAs purposes, certain issues need to be properly addressed. Two key areas, among others, are the efficient management of inorganic precipitates and the efficient thermal management of reactor heating and conversion rates.

\subsection{SCWO Background}

Proper waste management for long duration space missions has remained a long standing technical challenge for mission planners due to the increased emphasis on resource reclamation and the minimization of mass associated with any extended space exploration mission. Even short duration human space missions, such as the past missions of Skylab and Space Shuttle, and the current science missions carried out on the International Space Station (ISS), generate a considerable amount of waste. This waste is usually wet, voluminous, and biologically unstable with the major constituents comprising plastics (about $30 \%$ on average) and water (also approximately $30 \%$ ).

The water in the waste comes from a combination of food residues stuck to food pouches, hygiene wipes, and free liquids remaining in the drink pouches after consumption. It has been estimated that for a Lunar outpost each inhabitant generates between $6.8 \mathrm{~kg}$ to $9.6 \mathrm{~kg}$ of waste per day. [2] Waste accumulation remains a significant problem and will require serious attention in the planning and design for the long duration space exploration missions currently envisioned; particularly with the Mars transit mission. In order to reduce any waste management system's total equivalent system mass it will be important to consider technologies that will handle cross-cutting objectives allowing resource reclamation from both wet and solid waste streams. Regenerative systems such as those designed to grow plants for food will require extensive resource reclamation; e.g., carbon dioxide, water and plant nutrients. Ideally, these resources will be recoverable from any waste management system treating bio-waste streams in order to be practicable.

Due to the dramatic change in the properties of water near its critical point $(\mathrm{Tc}=647.096 \mathrm{~K}, \mathrm{Pc}=210 \mathrm{~atm})$ it becomes a highly advantageous medium for carrying out oxidative reactions with hydrocarbons. Water, which is a polar molecule at ambient conditions, begins to lose its polarity and as a result its propensity for hydrogen bonding and increasingly behaves like an organic molecule where intermolecular forces are dominated by Vander Waal forces. Since solubility is a balance between the intermolecular forces of the solvent and the solute, as water loses its propensity for hydrogen bonding it increasingly becomes a solvent of organic material and decreasingly acts as a solvent for other ionically attracted molecules. Gases (e.g., $\mathrm{O}_{2}, \mathrm{~N}_{2}, \mathrm{CO}_{2}$ ) and organics become highly soluble in water and salts will fall out of solution. Additionally, the density of water and transport properties such as viscosity, conductivity and mass diffusion will begin to resemble that of a dense gas as shown in Figure 1. 
SCWOs primary technical challenge has been the insolubility of inorganic salts in supercritical water. Precipitation of these inorganics occurs in the near-critical and supercritical regime due to an order of magnitude decrease in the dielectric constant of water compared to its value under room conditions (i.e. $\xi=80$ at $\mathrm{T}=300 \mathrm{~K}$ compared to $\xi=5.4 \mathrm{atTc}$ ). The Debye ionic screening distance, which is the distance beyond which interactions between differently charged ions are not felt, is proportional to $\xi^{1 / 2}$. So, as the dielectric properties of water decrease at near-critical conditions the ionic charges are not well shielded, leading to ionic recombination and eventual agglomeration of the salt precipitate. These agglomerated salts will then concentrate in the effluent stream and develop deposits in narrow flow passages and other internal reactor surfaces leading to clogging, impaired heat transfer, and an overall decrease in operating efficiencies. Additionally, if the waste stream contains chlorine or other halogens, supercritical water effluents can become acidic leading to corrosion of the reactor vessel.

The primary advantage of SCWO is its ability to carry out oxidative reactions at very high reaction rates on organic contaminants in wet waste streams. $[4,5]$ This includes waste streams ranging from gray water to slurries heavily loaded with mixtures of organic and inorganic solids. [6]

SCWO is therefore a very attractive technology for processing solid entrained liquid waste streams since (i) pre-drying of waste is not required, (ii) product streams are benign, microbially inert, and easily reclaimed, (iii) organic waste conversion is complete and relatively fast, and (iv) with proper design and operation, reactions can be self-sustaining. In addition, because of the absence of inter-phase reactant transport, due to the single phase nature of SCWO processes, reaction timescales are greatly reduced and many of the complications associated with two-phase transport and processing in reduced gravity environments are eliminated.

Since all extraterrestrial SCWO applications will operate in a reduced gravity environment, gravitational influences on (i) reactant mixing, (ii)reaction rates, (iii) waste stream preparation, and (iv) planned or unplanned autoignition of hydrothermal flames during autoignition [7] are among some of the issues that need to be thoroughly understood. Earth-based experiences can not be easily extrapolated and/or refined for design of extraterrestrial systems. These gravitational effects are, as yet, largely unexplored and provide the motivation for the focus of this work.

\subsection{Historical Perspective}

The three flight investigations, the SCWM experiment, the SCWM-2 experiment, and the SCWO-D experiment (i.e., the SCWO investigation performed in the DECLIC-Evo) are all successors of the original flight investigation, the HTI investigation, which carries the same name as the original insert hardware. The HTI was designed to accommodate high temperatures and pressures to study the near-critical behavior of pure water under a variety of heating profiles and temperature non-uniformities.

The HTI experiment was completed in the Fall of 2010 and was subsequently followed by the SCWM experiment, which was the first collaborative investigation between NASA and CNES designed to study 
near-critical behavior of dilute aqueous solutions of salt. This experiment, from its inception, along with its follow-on experiment, SCWM-2, were intended to serve as a set of precursor experiments with the ultimate objective of performing a microgravity SCWO investigation, which would require a different insert.

To accomplish the first of the two SCWM investigations the HTI was returned for refurbishment and subsequently renamed the HTI-Refurbishment (HTI-R) and returned to the ISS with a dilute salt-water solution (0.5\%-w sodium sulfate) in the Sample Cell Unit (SCU), which is the closed and thermally isolated high pressure observation cell. Images of the HTI-R experimental cell and the SCU are shown in Figure 2.

The overarching objective of the SCWM and SCWM-2 experiments was to observe the formation of salt precipitates and their transport mechanisms at near-critical conditions in both isothermal and noncurrently underway. ${ }^{1}$ This experiment is further discussed in Section 2.

The HTI-R was launched with the ATV-4 in June 2013 and the SCWM experiment was first operated in July 2013. There were a total of eleven test sequences (typically spanning about 18 days of continuous operations) that were performed with some of these either partially, or in total, devoted to engineering checksuspended for a little over two years, from Apr-2014 to Nov-2016 and occurred between Test Sequence 05 (HTI-R 11) and Test Sequence 06 (HTI-R 12). This was due to a failure in the communication link between the DECLIC Control Locker and the DECLIC Experiment Locker, requiring that the DECLIC Facility be returned to the ground for repair. SCU was refilled with a new test solution, which is to be decided once the final analyses are completed from the results obtained in SCWM. A test solution currently envisioned will be a ternary solution comprising a dilute salt-water solution in the presence of $\mathrm{CO}_{2}$, intended to simulate a typical product stream in a SCWO process reactor.

Unfortunately, SCWM-2 was postponed due to a failure of a critical optical diagnostic that was required for other DECLIC experiments. It was decided to return the DECLIC Facility for repair and refurbishment and to relaunch it as the DECLIC Evo, where Evo suggests evolutionary because it will not only accommodate the existing suite of DECLIC experiments but will be capable of accommodating an evolved suite of potentially seven new experiments, one of which is SCWO-D.

The SCWM and the SCWM-2 experiments are motivated by one of the major technological challenges associated with conventional SCWO reactors. This is the rapid and abundant precipitation of inorganic salts that occur in supercritical water, leading to significant reactor fouling, corrosion and inefficient operation. The investigation is designed to obtain insights into a salt precipitates incipient size and structure, its

${ }^{1}$ Preliminary results have been submitted for publication. 
tendency to agglomerate, and its dominant transport mechanism in the presence of temperature gradients.

\subsection{Summary of Preliminary Results}

Analysis of the data from the SCWM flight experiment is still underway and early results have just been submitted for publication. In an interim report, while testing was still underway, it was noted that the dilute solution of $\mathrm{Na}_{2} \mathrm{SO}_{4}$ aq $0.5 \%$-w salt water behavior was markedly different than pure water. Comparisons supercritical temperatures. The critical temperature of the salt water mixture was found to be higher than that of pure water and the repeatability of this measurement was not as precise as it was with pure water when the critical point was traversed multiple times. This suggests there may have been some poorly understood physical process due to the presence of the salt and/or due to an irreversible process; e.g., formation of a are underway to perform an analysis of the solution concentration to help resolve this issue. 
Another noteworthy finding was the dramatic difference in incipient boiling. In the salt water solution boiling began at approximately $645 \mathrm{~K}$ and was characterized by very tiny uniformly sized bubbles (approximately 20 micron in diameter) and rather than traveling in a random trajectory, instead formed bubble channels emanating from the test cell walls. These channels directed the bubble's trajectory radially inward toward the liquid-vapor meniscus, which forms a single large vapor bubble in $0-\mathrm{g}$.

Other observations include (i) the coupling of phase separation (i.e., salt-water-liquid partitioning) with the rate of heating as the system transitions from sub-critical to supercritical, (ii) the persistence of a dark crescent shaped region in the monophasic, near critical regime, and (iii) a relationship between the transcritical approach heating rate and the stability of the large vapor bubble. These phenomena are still under evaluation and will be discussed in further detail in an article that is being prepared for publication.

\section{SCWM-2}

An additional re-flight of the High Temperature Insert (HTI-R2) is planned soon after the DECLIC-Evo Facility is operational on the ISS. There are three possible experiment configurations that are of interest and the ultimate definition of SCMW-2 will largely depend on the final conclusions reached from the on-going analyses of the SCWM data. Since these options are completely hardware independent a final decision is not necessary until it is time to fill the SCU. These options are discussed as follows:

Option 1 A Non-precipitating Type 1 Salt (e.g., NaCl) Solution: The first high temperature insert re-flight, the HTI-R, provided for the SCWM experiment, which investigated the precipitation and dissolution of a dilute Type-II salt-water $\left(\mathrm{Na}_{2} \mathrm{SO}_{4}\right)$ mixture during the transition from sub-critical to supercritical (as well as the reverse phase transition) and the transport of the precipitate under a temperature gradient. Option 1 proposes, instead, a Type 1 salt (e.g., $\mathrm{NaCl}$ ) which has a much higher solubility near the critical point than a Type 2 salt. This would enable the study of critical temperature shift, turbidity, equilibration phenomena and transport in the presence of a temperature gradient in a salt-water solution in the absence of precipitate. In conjunction with the original pure water experiment, the HTI, and the SCWM experiment this option would provide complementary data for what has already been obtained in microgravity for pure water and for a Type 2 salt solution as it transitions through the critical point. This is important since practical supercritical water oxidation systems generally have both Type 1 and Type 2 salts.

Option 2 A Ternary Salt-Water- $\mathrm{CO}_{2}$ System: Since a major product of supercritical water oxidation

is $\mathrm{CO}_{2}$ this option will enable the simulation of salt behavior and transport in a practical SCWO system. The choice of Type1 or Type2 salt will be made depending upon the final conclusions of SCWM and further ground-based studies. This experiment will study the impact of $\mathrm{CO}_{2}$ on precipitation, the critical temperature shift and transport phenomena that is important for addressing reactor fouling. A complication that arises from this option is properly accounting for any irreversibility in the system due to reactions that 
may occur in high temperature/pressure $\mathrm{CO}_{2}$ systems. However, if this irreversibility can be accurately modeled it may provide a viable way for performing multiple experiments with a single baseline test solution.

Option 3 Dissolution of Organic Material in Near-Critical Water: Hydrogen bonding between water molecules, which is very strong at ambient conditions, decreases significantly as water approaches its critical point. The result is that organic compounds become highly soluble in supercritical water. This experimental option proposes the use of an organic material, non-soluble in liquid water, whose solubility undergoes a reversal in near critical water. The intent would be to study the mechanisms of organic solubility as water transitions from sub-critical to supercritical. The proposed experiment under this option would help provide an understanding of the phenomena associated with the dissolution and transport of an organic substance in water at near-critical conditions. The investigation will obtain the shift in critical point and will provide detailed observations of the dissolution and transport processes. Results will provide insights into the mechanisms that govern dissolution, transport and mixing of organic compounds in supercritical fluids. This experiment serves as an excellent precursor to the supercritical water oxidation investigation that is planned (SCWO-D) in that it will provide observations of the organic dissolution mechanism, the rate of dissolution and the primary transport processes of a reaction system prior to the reaction occurring. A difficulty with this option, similar to that with Option 2, is identifying a suitable organic material so that the dissolution process is reversible, or if not reversible, can be accurately modeled when water is returned to subcritical conditions.

\section{SCWO-D}

In order to extend the reach of SCWO technology for extraterrestrial application, a significant re-design of a conventional SCWO reactor will likely be required. One such design concept envisions a reactor where heating, fueled by the energetics contained in the waste stream, takes place within the reactor. This design is currently under consideration by NASA and is shown in Figure 5.

Here it is considered that heating internally with a stabilized hydrothermal flame may be sufficient to sustain supercritical temperatures within a localized region, the reactor core region. In this conceptual reactor design temperatures would decrease from the reactor core radially outward to the walls where subcritical conditions would be maintained. This concept suggests that any inorganic material (primarily salts) that may have precipitated from solution in the supercritical core would redissolve thereby minimizing the buildup of deposits on the surfaces.

The objectives of this experiment recognizes that, to date, there has been little work performed in the detailed analyses, modeling and testing, either on a component or system level, where the absence, or significant reduction, of gravitational forces has been evaluated for hydrothermal flames. Most of the necessary work that remains to be performed in order to make SCWO technology appropriate for space and/or extraterrestrial application lies in the realm of the thermal and fluid sciences. Topics such as phase 
separation, heat transfer, reactant transport, reaction kinetics, spontaneous flame ignition and reaction propagation will present unique challenges in a microgravity environment.

An example of the gravitational influence on SCWO processes is found in the determination of whether flames spontaneously ignite when a stream of reactants is introduced into the reactor. Traditionally SCWO has been considered a low temperature flameless oxidation process; however, the presence and persistence of hydrothermal flames have long been known to exist [8] and only recently have they become the subject of active research. It was found that these flames may be spontaneous and, under certain operating conditions, may be unavoidable [9]. The presence of these flames in a reaction vessel, if not properly controlled, could result in excessive local temperatures (i.e., temperatures exceeding 3,000C have been observed) that could damage unprotected component surfaces such as reactor walls, fluid injection nozzles, etc.

\subsection{SCWO-D Science Objectives}

The preceding discussion suggests the motivation for a broad scope of objectives in the SCWO-D investigation. This is summarized in four topical research areas which will be considered when drafting the science requirements that will guide the design of the new SCWO-D insert. These four areas are transport and solvation mechanisms, hydrothermal flames, reaction kinetics, and phase interface phenomena and are briefly discussed as follows:

1. Research focusing on transport phenomena and solvation mechanisms in both near critical and supercritical water regimes. These research topics would include:

(a) solubility mechanisms for binary phase aqueous mixtures of Type I and Type II salts and ternary phase aqueous mixtures (i.e., liquid-solid-gas) with soluble gases (e.g., $\mathrm{CO}_{2}, \mathrm{~N}_{2}$ ),

(b) the physical mechanisms of the dynamics of salt deposition on thermal control surfaces,

(c) effects of variations in mass/thermal diffusivities,

(d) the role of thermophoretic forces on particles in the presence of large temperature gradients.

2. Research focusing on hydrothermal flames that are dominated by buoyant forces in 1-g. To date, very little work on hydrothermal flames, both in 1-g and in 0-g, has been performed in the following areas:

(a) flame inception, stability and propagation,

(b) flame combustion in diffusion-limited and pre-mixed regimes,

(c) reduced chemistry models for key reaction mechanisms

(d) numerical and analytical modeling schemes for hydrothermal flames.

3. Research focusing on building a data base for reaction kinetics in near-critical and supercritical regimes. This includes the reaction kinetics and destruction efficiencies of typical constituents of bio-waste 
streams; $\mathrm{N}_{2}$ containing waste streams (e.g., urea, ammonia, acetic acid); and NOx mitigating schemes in high temperature reactions (flame combustion).

4. Research focusing on the hydrodynamics in 0 -g of injecting disparate fluid phases (i..e, sub-critical, trans-critical, supercritical) into a quiescent or non-quiescent bulk fluid at supercritical conditions.

\subsection{SCWO-D Groundbased Developmental Work}

In preparing for the SCWO-D flight investigation a considerable amount of work has already taken place to develop an understanding of the phenomena of interest and its interplay with buoyant forces. [10, 11, 12, $13,14,15]$ In a microgravity environment, many of the observed physical phenomena are significantly altered due to the very high density gradients that exist in a SCWO reactor. The elimination of buoyancy becomes both a necessary pre-condition for advancing the Technology Readiness Level (TRL) of this technology as well as an advantageous condition for observing phenomena in an environment that allows for deeper insights into the physical processes of interest.

An effort is also under way to develop the micro-fluidic technologies that will be necessary for the design of the SCWO-D insert. Due to the high pressures this experiment will be operating, the ability to achieve a broad range of science objectives, as proposed in the preceding section, depends largely on the ability to dramatically reduce the experimental length scale. A fluid infrastructure, potentially on the micro-scale, is currently envisioned that will support this effort.

\subsubsection{Hydrothermal flame testing}

The proposed SCWO-D flight investigation, particularly in light of the recent emphasis on new reactor designs incorporating hydrothermal flames, has a high degree of relevancy for both terrestrial and extraterrestrial systems. As suggested in Sec. 4 there is a largely unexplored, but important, nexus between traditional combustion research and the potential for making significant advances in SCWO technology.

In recent 1-g experiments, designed to investigate the spontaneous ignition processes of hydrothermal flames, a high pressure test cell is used and this is shown in Figure 6. This test cell is machined from Inconel 625 with a maximum design pressure of 340 noneatm at $538 \mathrm{C}$ and is described in further detail in an earlier publications. [14] For these tests a co-flow injector with a ratio of 16:1 between the annular and core flow areas was used.

A sequence of images is presented in Figure 7 from a hydrothermal flame ignition test that was performed in this test cell illustrating the dramatic influence buoyancy will have on these flames. [15] In this test the above described co-flow injector was used and both the air flow rate (annular region) and the fuel flow rate (core region) were $2.0 \mathrm{ml} / \mathrm{min}$. The fuel was $50 \%-\mathrm{v} \mathrm{C}_{2} \mathrm{H}_{6} \mathrm{O}$ (aq) and the fuel injection velocity was $12 \mathrm{~cm} / \mathrm{s}$ resulting in an injection Reynolds number of $\mathrm{Re}=1100$.

The images in the upper row are shadowgraph images and the images in the bottom row provide color images of the flame with the color camera's focal plane at an orthogonal orientation with the focal plane 
in the upper row. Each image in the upper row is synchronized in time with the image immediately below

and the time lapse between images is selected to highlight distinct phases of the ignition process. Here in Figure 7 a the flame initiates in the downstream section of the flow stream where the reactants are well mixed. The flame then propagates upstream and as it propagates closer to the burner there is significant laminarization of the flow in the downstream regions. This may be due to the local increase in temperature which leads to an increase in the local viscosity [16]. Additionally, there is a localized temperature increase where the flame first appears, due to the heat of combustion, causing a rapid expansion of the supercritical fluid in this zone. This rapid expansion results in buoyantly induced acceleration of the jet stream which enhances mixing and increases the intensity of the localized reaction. As a result the localized reaction rate increases and the flame velocity becomes larger than the buoyantly enhanced flow velocity. At this point the flame begins to propagate upstream into the unburned mixture where it is eventually stabilized at the burner.

\section{Summary}

A series of microgravity investigations designed to provide deeper insights into some of the fundamental processes that take place in water at near-critical conditions are discussed. This suite of experiments are the SCWM, which has already been conducted on the DECLINE Facility, and the SCAM-2 and SCWO-D, which are in development and planning phases, respectively, and are to be conducted on the DECLIC-Evo Facility. These individual flight investigations represent a systematic sequence of experiments designed to provide deeper insights into fundamental processes that take place in water at near-critical conditions and ultimately to observe and characterize hydrothermal flames in a 0 -g environment. This work is performed, in part, to help advance SCWO technology for eventual application in a reduced gravity environment. SCWO technology is one of NASAs candidate technologies for waste management and resource reclamation for extraterrestrial missions.

The status of each flight investigation has been discussed and where results have been obtained, as in the case of the SCWM investigation, a short summary of some of the preliminary findings have been presented. The SCWM experiment was designed to provide observations of the phase separation and transport mechanisms of salt precipitate in a dilute solution of $\mathrm{Na}_{2} \mathrm{SO}_{4} 0.5 \%$-w (aq) at 0 -g. The SCWM-2 experiment is a follow-on experiment designed to expand on the science obtained in SCWM using the same insert filled with a different test solution. The third microgravity experiment, SCWO-D, is designed to allow for observations of autoignition and stabilization of hydrothermal flames in supercritical water. Because of the unique science requirements posed by this investigation this experiment will require a significant insert redesign to accommodate a flow system and a test cell to allow for observations of small hydrothermal flames without quenching.

Additionally, significant development work has been underway in support of the science associated with 
the generation and stabilization of hydrothermal flames. The science team at the University of Bordeaux is developing the micro-fluidic devices to support the miniaturized infrastructure for the flow system. The and stabilization of hydrothermal flames.

\section{Acknowledgments}

This work is funded under the Space Life and Physical Sciences Research and Applications (SLPSRA) program directed by Dr. Craig Kundrot. The physical sciences content is selected, managed and advocated by managed by Dr.

[7] Roberto M. Serikawa, Takashi Usui, Tatuya Nishimura, Hirokazu Sato, Shusaku Hamada, and Hideo Sekino. Hydrothermal flames in supercritical water oxidation: investigation in a pilot scale continuous reactor. Fuel, 81(9):1147 - 1159, 2002. 1.1 
[8] E. U. Franck. Aqueous mixtures to supercritical temperatures and at high pressures. Pure and Applied

[15] Michael C. Hicks, Uday G. Hegde, and Jun J. Kojima. Hydrothermal ethanol flames in co-flow jets. The Journal of Supercritical Fluids, 145:192 - 200, 2019. 4.2, 4.2.1, 7

[16] M. Ihme and H. Pitsch. Effects of heat release on turbulent jet flows. page 991996, Munich, Germany, 2007. 4.2 .1 


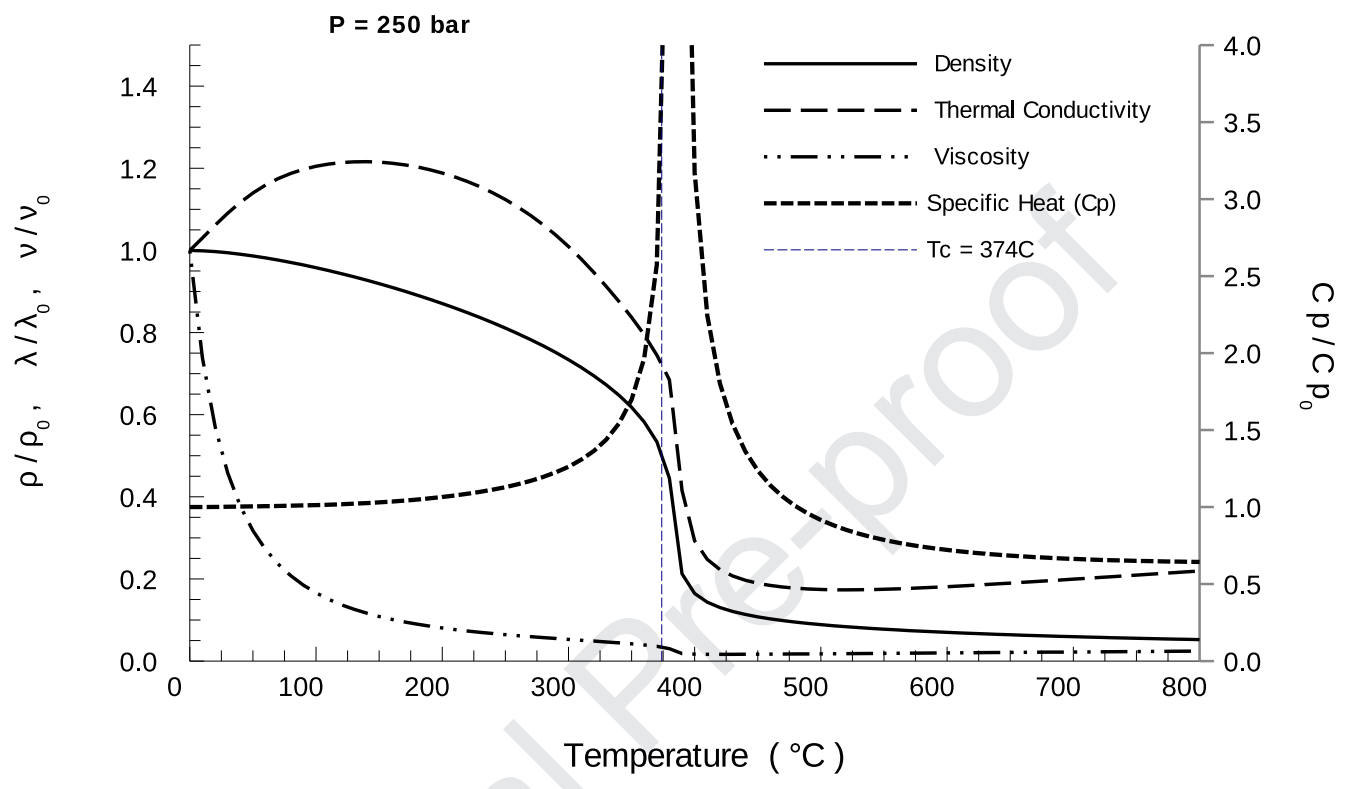

(a)

\begin{tabular}{lccc}
\hline \multicolumn{1}{c}{ Phase } & $\begin{array}{c}\text { Density } \\
\rho\left(\mathrm{kg} / \mathrm{m}^{3}\right)\end{array}$ & $\begin{array}{c}\text { Viscosity } \\
\eta(\mathrm{mPa}-\mathrm{s})\end{array}$ & $\begin{array}{c}\text { Diffusivity } \\
\mathrm{D} \times 10^{6}\left(\mathrm{~m}^{2} / \mathrm{s}\right)\end{array}$ \\
\hline Gases (ambient) & $0.6-2$ & $0.01-0.03$ & $10-40$ \\
SCF's at Tc, Pc & $200-500$ & $0.01-0.03$ & $\approx 0.1$ \\
SCF's at Tc , 4xPc & $400-900$ & $0.01-0.09$ & $\approx 0.02$ \\
Liquids (ambient) & $500-1600$ & $0.2-3$ & $0.0002-0.002$
\end{tabular}

(b)

Figure 1: (a) Properties of water at $\operatorname{Pr}=1.5$ and normalized by values at ambient conditions and (b) a comparative table reproduced from Supercritical Water - A Green Solvent:Properties and Uses [3] displaying properties of supercritical fluids at pressures of Pc and 4 Pc. 


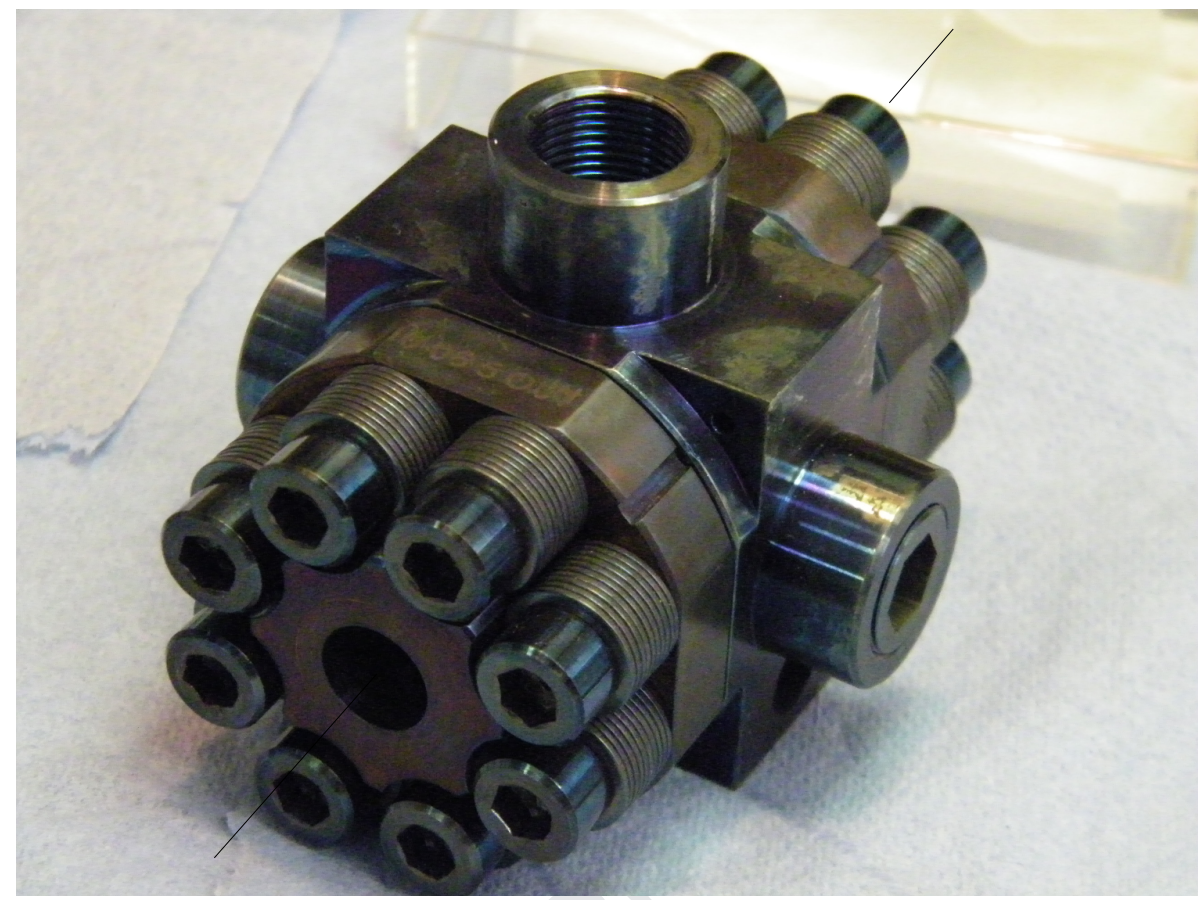

(a)

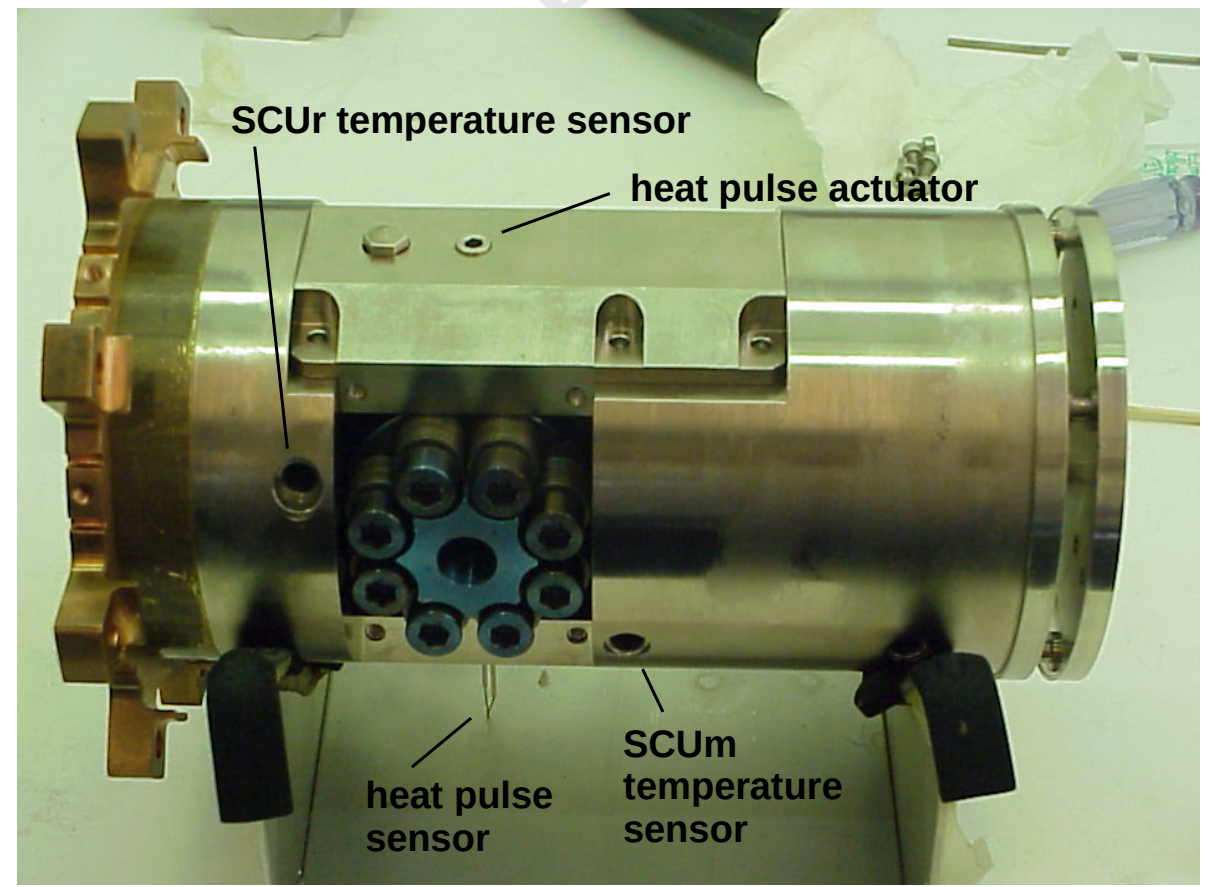

(b)

Figure 2: (a) Experimental cell made from Inconel 718 with a test volume of approximately $0.3 \mathrm{~cm}^{3}$ and two sapphire windows ( $8 \mathrm{~mm}$ diameter) aligned in the image orthogonal to the axis shown and (b) Sample Cell Unit (SCU) comprising the experimental cell in its housing fabricated from copper block for tight thermal regulation. 
High Temperature Insert (HTI / HTI-R I HTI-R2)

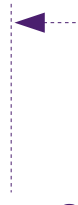

SCW I HTI (2013)
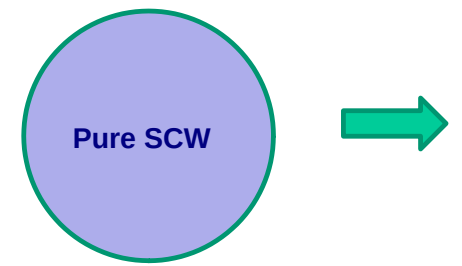

single phase system
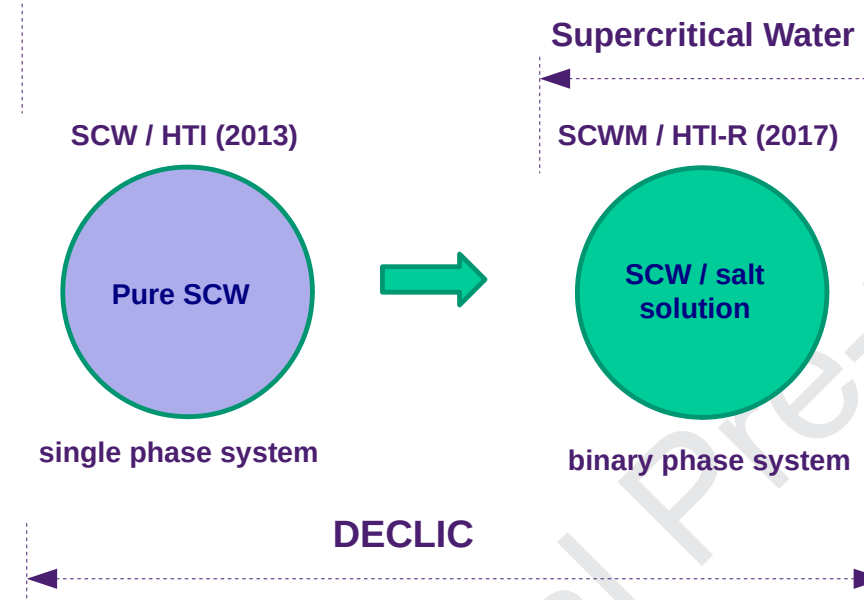

binary phase system

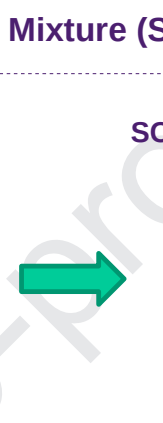

V) Experiments
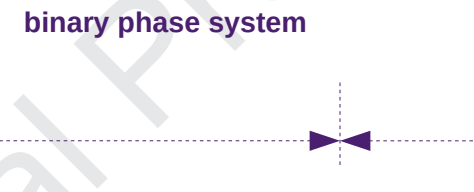

CWM-2 I HTI-R2 (ca. 2021)

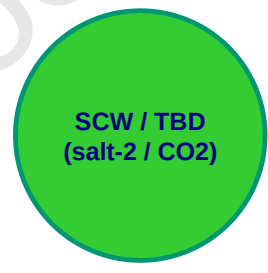

binary or ternary

phase system
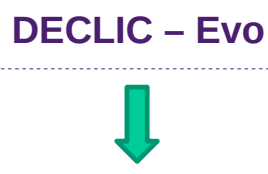

SCWO-D (ca. 2025)

\section{SCWO-D / SCWO Insert}

- new SCWO insert designed and built by CNES

- micro-fluidic infrastructure for insert design

- macroscale test cell for hyrdothermal flames

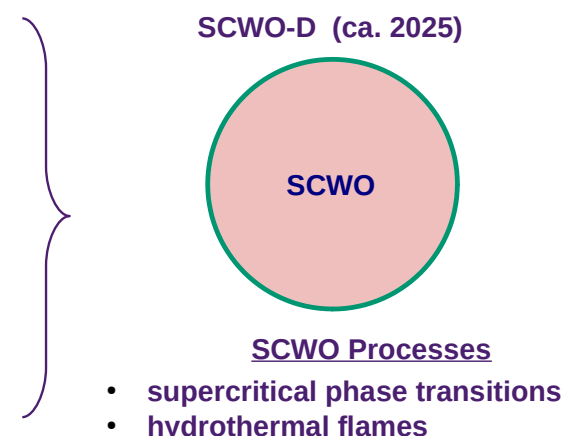

Figure 3: Schematic illustrating the relationship of the individual SCWM investigations (experiment name/insert name) and their approximate timeline. 


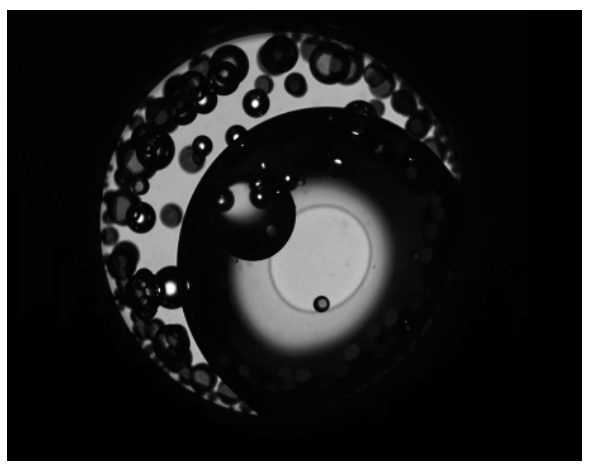

(a)

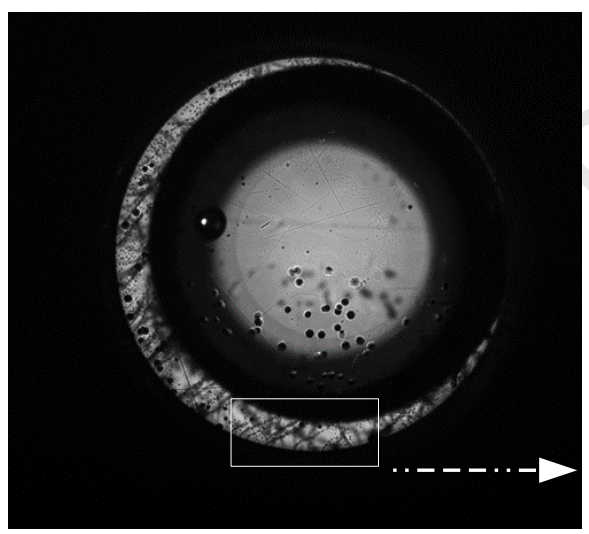

(c)
Sample Cell Unit (SCU)

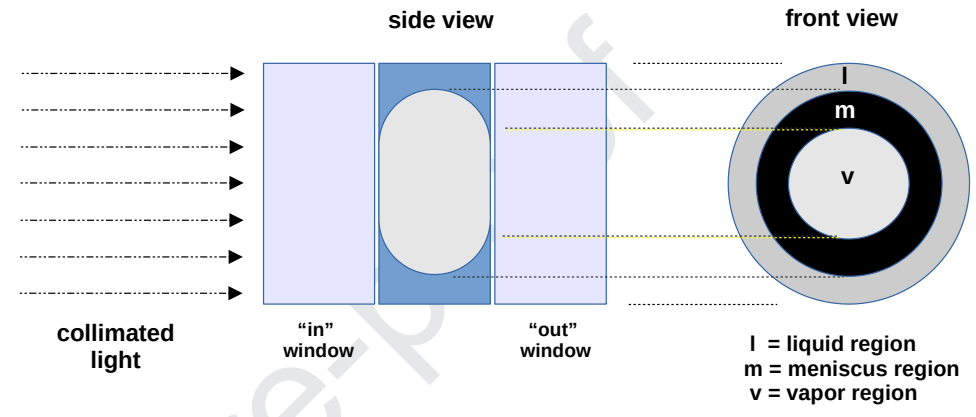

(b)

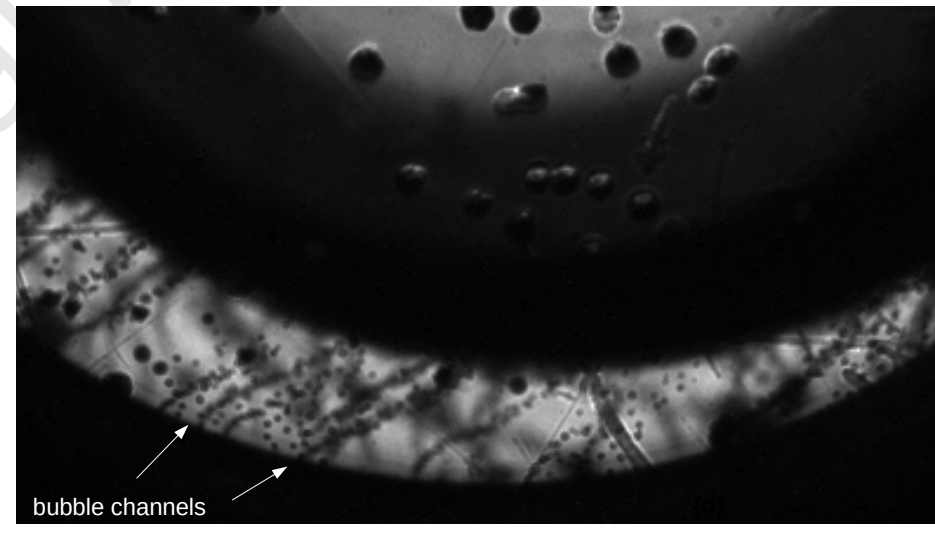

(d)

Figure 4: Images showing comparison of incipient boiling of (a) pure water and (c) $\mathrm{Na}_{2} \mathrm{SO}_{4}(\mathrm{aq}) 5 \%$-w and (d) the enlarged inset to show the vapor channels comprising small vapor bubbles moving radially inward from the heated surface to the liquid-vapor meniscus. The schematic (d) provides an explanation of the view that is presented in the images. 

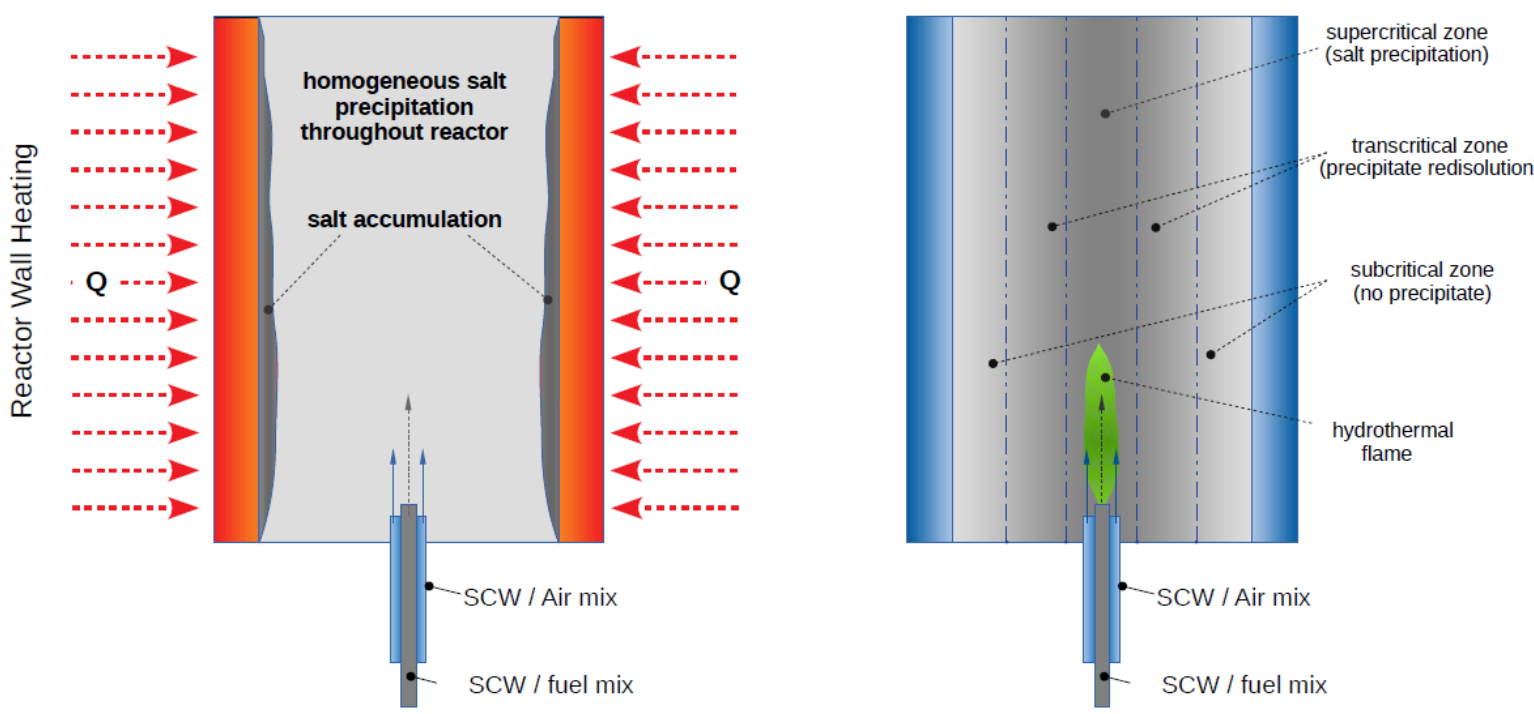

Figure 5: Comparison of two reactors where (left) a conventional SCWO reactor is shown heated from the exterior with reactor walls kept at temperatures above Tc and (right) a non-conventional design where reactor walls are maintained at sub-critical temperatures and heating is achieved with a stabilized hydrothermal flame fueled from the energetics of the waste stream. 


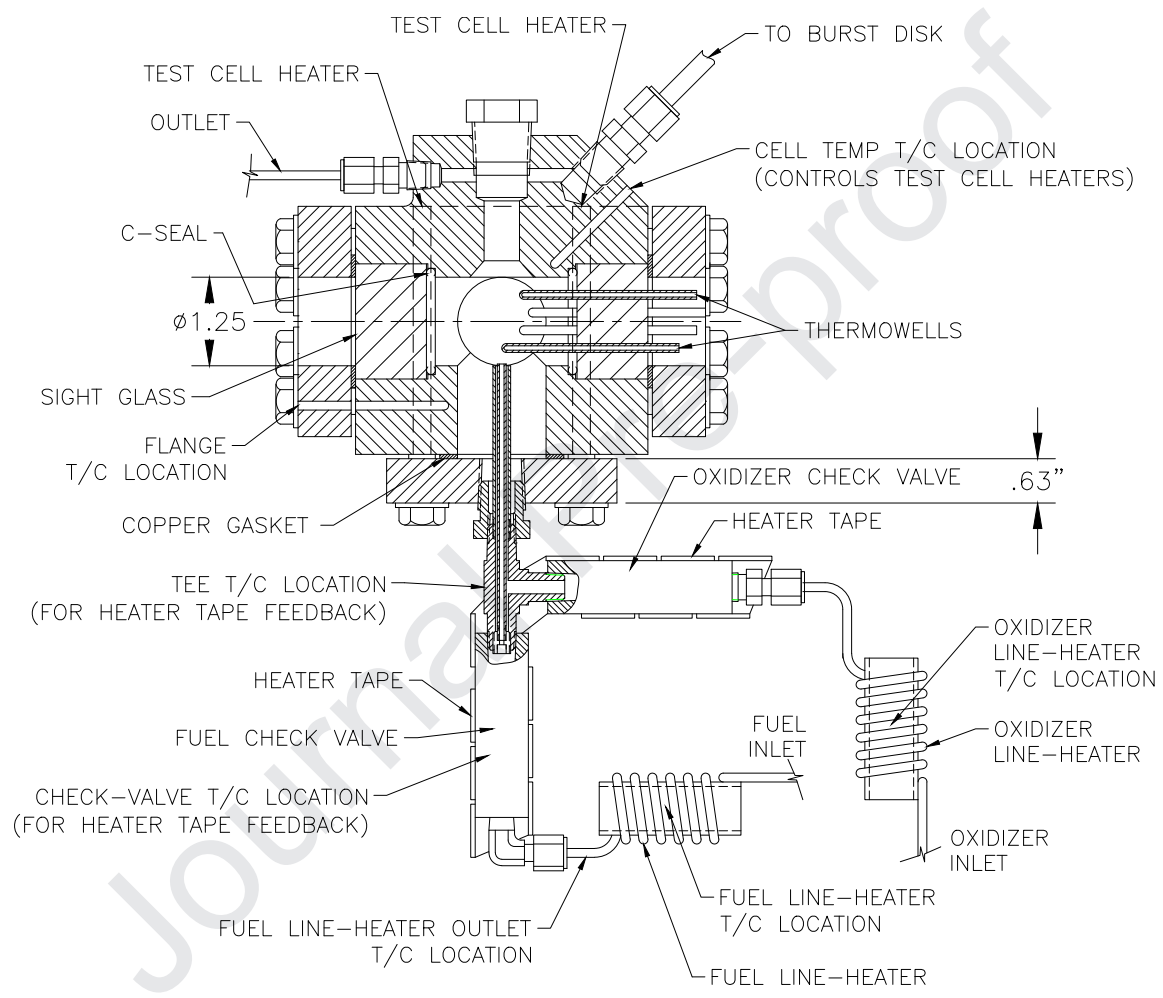

(a)

Figure 6: Schematic showing the SCWO Test Cell in a three window test configuration comprising orthogonal view ports with one axis (into paper) used for back-lit shadowgraphy (collimated backlight projecting a shadow image into a high resolution $\mathrm{B} / \mathrm{W}$ camera) and the orthogonal axis used for flame imaging (left side of cell) and the opposing side used for four thermowells protruding into the flame zone. 

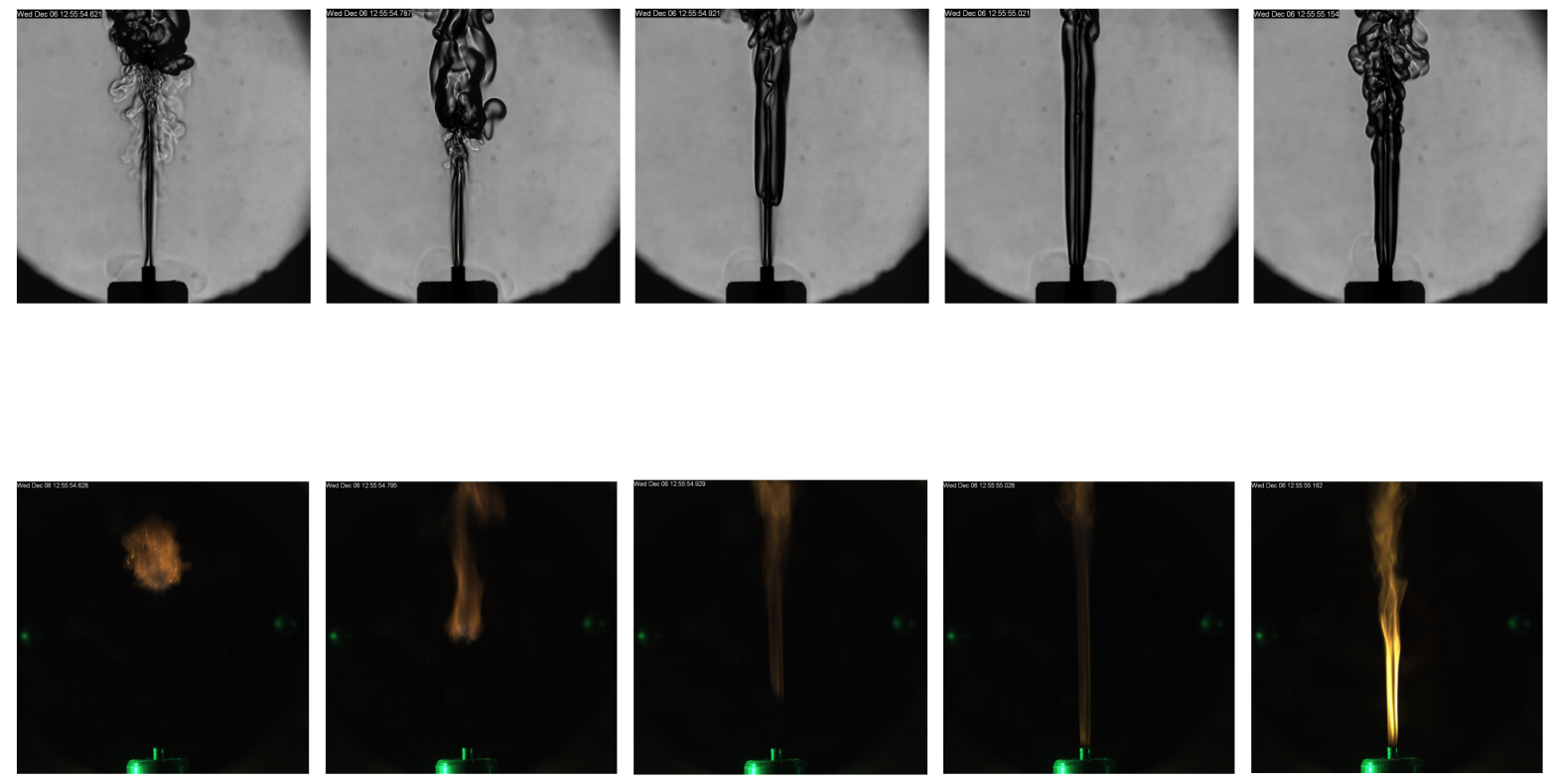

(a)

(b)

(c)

(d)

(e)

Figure 7: Series of images showing formation of flame kernel, upstream flame propagation and stabilization of the diffusion flame for the $2 \mathrm{ml} / \mathrm{min}$ air co-flow case; where (a) reference time $\mathrm{t}=0 \mathrm{~s}$, (b) t $=0.166 \mathrm{~s}$, (c) $\mathrm{t}=0.300 \mathrm{~s},(\mathrm{~d}) \mathrm{t}=0.400 \mathrm{~s}$, and (e) $\mathrm{t}=1.53 \mathrm{~s} \cdot[15]$ 


\section{Highlights:}

- Near-critical water phenomena studied on the International Space Station.

- Dilute salt solution shows differences in boiling and critical phase transition.

- Spontaneous ignition and stabilization of hydrothermal flames is observed.

- Use of hydrothermal flames for advanced supercritical water reactors is proposed. 


\section{Declaration of interests}

$\mathrm{X}$ The authors declare that they have no known competing financial interests or personal relationships that could have appeared to influence the work reported in this paper.

$\square$ The authors declare the following financial interests/personal relationships which may be considered as potential competing interests: 